\section{My Two-Dimensional Life}

T hanks to COVID-19, I am still sheltering in place in San Francisco, wondering if I will ever again be able to get a haircut or hug a friend that I meet on the street. Some states are "opening up" while cases of COVID-19 are still climbing, and new projections are that deaths will again escalate and restrictions will be put in place again. So, I'm concerned that we will be under restrictions for a very long time. I hope I'm wrong and that by the time you read this, we will have many of our freedoms back, and, along with that, the promise of a vaccine to keep this enemy at bay.

Of course, since I'm spending all my time working from home, doing Zoom meetings and telemedicine, I've had a bit of time to reflect on changes we had to make. Sometimes disruption and dynamic changes can lead to some positive outcomes. At least, we hope these will. So, here is my take on these changes.

First, the personal: Since I am a champion Luddite, actually mastering telemedicine-video visits on my iPad, my electronic record open on my laptop, with my nurse on my speaker phone-was a major achievement for me. I can do this! Not only that, I can "Zoom" into meetings effortlessly, and I have even learned how to project myself in front of the Golden Gate Bridge or from outer space. Nothing short of a miracle!

But do I like these changes from a professional standpoint? Let's take Zoom meetings for a start. They are definitely convenient and efficient. The University of California, San Francisco is a pretty widely distributed organization, interspersed throughout San Francisco. Being able to attend meetings remotely saves a lot of time. Since it doesn't matter where you are, you can still participate even when traveling.

But are you fully present and engaged? I don't think so. In most of our Zoom meetings, half the participants block their videos. That may be because they don't want you to see that they are still in their pajamas, but it also allows for checking email or enjoying other distractions instead of focusing on the work at hand. Meeting in person is so much better when it's possible. It allows for sidebar discussion and friendly exchanges that are so important in reinforcing relationships. My takeaway is that we will conduct more meetings remotely in the future because of cost and efficiency, but these will never replace the "real deal" when it's possible to meet in person.

Telemedicine has different benefits and downsides. On the upside, patients can receive care in the comfort of their own homes and theoretically have an army of family members present for the visit. They can avoid the exhaustion of travel, often compounded by bumper-to-bumper traffic on virtually every access to and exit from San Francisco. From my perspective, the visits seem shorter and I have more time for reviewing data and charting. On the downside, I can't check any vital signs, listen to their lungs, check lymph nodes, or examine their abdomens-key diagnostic maneuvers for me. But the biggest downside is emotional. It is hard to express deep empathy in 2 dimensions. I can't hold a hand, wipe away tears, or provide a comforting hug. It is very hard for me and, I suspect, hard for the patients. As the old song goes, people really do need people. In 3 dimensions. I know telemedicine is here to stay, but please, not for every single visit!

You'll have to excuse me now as I have another Zoom meeting to attend. Thank you for listening! JNCCN@nccn.org or log into www.editorialmanager.com/JNCCN.

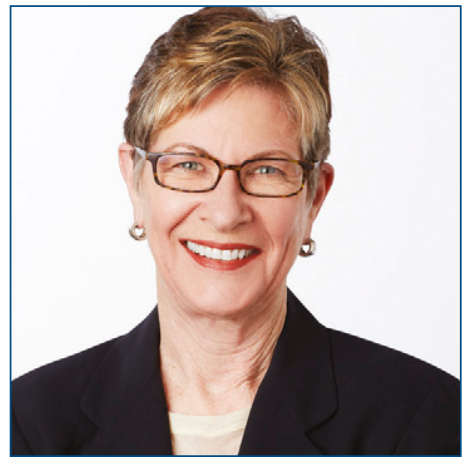

MARGARET TEMPERO, MD

Margaret Tempero, MD, is a Professor of Medicine and Director of the UCSF Pancreas Center and editor-in-chief of JNCCN. Her research career has focused on pancreatic ductal adenocarcinoma, especially in the area of investigational therapeutics. Dr. Tempero has served on the ASCO Board of Directors and as ASCO President. She currently serves on the ASCO Conquer Cancer Foundation Board. She codirected the AACR/ASCO Methods in Clinical Cancer Research and taught this course and similar courses in Europe and Australia. She was founding Chair of the $\mathrm{NCl}$ Clinical Oncology Study Section and served as a member and Chair of the $\mathrm{NCl}$ Board of Scientific Counselors Subcommittee A. She is a member of the Scientific Steering Committee and Chair of the Clinical and Translational Study Section for the Cancer Prevention \& Research Institute of Texas. She is or has been on the Scientific Advisory Boards of the Lustgarten Foundation, the Pancreatic Cancer Action Network, the V Foundation, The Alberta Canada Cancer Board, and the EORTC. She served as a member of the Oncology Drug Advisory Committee for the FDA. She has served as Deputy Director and Interim Director for the UNMC Eppley Cancer Center. She is Chief Emeritus of the Division of Medical Oncology at UCSF. She served as the founding Deputy Director and was later Director of Research Programs at the UCSF Helen Diller Family Comprehensive Cancer Center.

doi: $10.6004 /$ jnccn.2020.0028

The ideas and viewpoints expressed in this editorial are those of the author and do not necessarily represent any policy, position, or program of NCCN. 